\title{
Predictors of Otoacoustic Emission Test in Newborns: A Prospective One Year Study in Ahvaz, Iran
}

\author{
Mozafar Sarafraz ${ }^{1}$ and Somayeh Araghi ${ }^{2 *}$ \\ ${ }^{1}$ Associated Professor of Otolaryngology, Head and Neck Surgery, Hearing \& Speech \\ Research Centre, Ahvaz Jundishapur University of Medical Sciences, Ahvaz, Iran. \\ ${ }^{2}$ Resident of otolaryngology, Head and neck surgery, Hearing \& Speech Research \\ Centre, Ahvaz Jundishapur University of Medical Sciences, Ahvaz, Iran.
}

DOI: http://dx.doi.org/10.13005/bbra/1928

(Received: 03 August 2015; accepted: 11 October 2015)

\begin{abstract}
Hearing loss compromises optimal development of language and communication unless effective intervention is started within the ûrst year of life. Despite the JCIH recommendation as universal screening of all infants for hearing loss within the first few months of life; only some countries were successful in executing it. This study was undertaken in order to determine the most important predictors of Otoacoustic emission (OAE) as initial hearing screening of infancy in south of Iran. This may help in targeted hearing screening in high risk infants. The present study is a prospective cohort study examining all newborns throughout 2013to2014 delivered in Emam Khomeini hospital, Ahvaz, Iran. The neonatal hearing screening was carried out by portable transient evoked automated otoacoustic emissions (OAE) before discharge from the hospital. The Association between probable predictors (birth weight, history of blood exchange due to Hyperbilirubinemia, family history of hearing loss and history of admission in neonatal intensive care unit (NICU) for more than 48 hours) and the rate of failure in the screening was then analysed. During the study, 1850 children were born in the maternity ward of this hospital. The frequency of hearing screening refers rate was obtained at $9.8 \%$. history of NICU admission and Low birth weight $(<1500 \mathrm{gr})$ were significantly associated with hearing impairment as measured by OAE $(\mathrm{P}<0.001$ for both of them). History of blood exchange due to Hyperbilirubinemia and positive family history were not significantly different between two groups. History of NICU admission and low birth weight are two significant predictors for OAE failure in south of Iran. So if universal newborn hearing screening is unavailable, targeted screening in high risk infants including those admitted to the NICU and newborns with low birth weight is highly recommended.
\end{abstract}

Key words: Predictors, Otoacoustic, Emission, Study.

Hearing loss compromises optimal development of language and communication unless effective intervention is started within the first year of life, preferably before six months of age $^{1,2}$. It is among the most common congenital disabilities ranging from 1-3 per 1000 low-risk newborns; however the prevalence is considerably greater in high-risk infants ${ }^{3}$

\footnotetext{
* To whom all correspondence should be addressed. Fax: +986132921838;

E-mail :savesina@yahoo.com
}

In 1994, the US established the Joint Committee on Infant Hearing (JCIH) recommended screening of high risk babies for hearing loss utilizing High Risk Registries ${ }^{4}$. Several studies thereafter suggested that up to $50 \%$ of all the children with congenital hearing loss have no risk factors and would be missed by screening only those at high risk. This made JCIH to change its recommendation in their 2000 position statement to universal screening of all infants for hearing loss within the first few months of life ${ }^{5}$. However, this recommendation is not globally achieved yet, and 
in the developing world only some countries were successful in executing previous recommendations.

This study was undertaken in order to determine the most important predictors of Otoacoustic emission (OAE) as initial hearing screening of infancy. This may help in targeted hearing screening in high risk infants. The study also presents the OAE refer rate in this pilot screening program. To our knowledge, this is among the first articles from south of Iran, evaluating risk factors of the neonatal hearing screening program.

\section{MATERIALANDMETHODS}

The present study is a prospective cohort study examining all newborns throughout 2013 september to 2014 october delivered in Emam Khomeini hospital, Ahvaz, Iran. Each infant was enrolled after obtaining informed consent from parents. This project was approved by the Ethics Committee of Ahvaz University.

The neonatal hearing screening was carried out by portable transient evoked automated otoacoustic emissions (OAE) before discharge from the hospital. OAE was carried out in both ears using a portable device which uses click stimuli involving frequency bands between $1,500 \mathrm{~Hz}$ and $3,800 \mathrm{~Hz}$. The click is presented at an intensity of 75 to $83 \mathrm{dBpeSPS}$. The response was considered positive (passed) when the otoacoustic emissions captured were $6 \mathrm{~dB}$ higher than the noise.

If there was no clear emission in either ear, infants undergo secondary testing with the OAE. In Absence of emissions in secondary OAE, infants were referred to a secondary institute to be tested with the auditory brainstem response (ABR). Measurement of ABR produced by a series of clicks at 36, 45, and $60 \mathrm{~dB}$ NHL was made via three scalp electrodes, an averaging computer, and a printer. The presence and latency of the ABR were determined by a trained observer. Screening was done by two trained audiologists under the supervision of an otorhinolaryngologist.

We collected the following information regarding the risk factors for hearing impairment by direct interview with the parents: birth weight, history of blood exchange due to Hyperbilirubinemia, family history of hearing loss and history of admission in neonatal intensive care unit (NICU) for more than 48 hours.

We analyzed demographic and clinical characteristics of the newborns enrolled in this study and the rate of failure in the screening. The association between failure in the test and birth weight, history of blood exchange, family history of hearing loss and history of admission in NICU were also examined. Result of secondary OAE and ABR were gathered but aren't reported in the present study.

Data from questionnaire and the results of the OAE were analyzed by Statistical Program for Social Science (SPSS- Version18). The investigation of the factors associated with $\mathrm{OAE}$ test failure was carried out by a univariate analysis, using the chi-squared or Fisher's exact test, considering $p<0.05$ as significant.

\section{RESULTS}

During the study, 1850 children were born in the maternity ward of this hospital. The screening program was carried out in all of the newborns (100\%) as a free optional process before discharge. The frequency of hearing screening refers rate was obtained at $9.8 \%$. The prevalence of potential risk factors is shown in Table 1.

Of the 1850 who underwent initial screening with the OAE, 1667 (90.2\%) passed the initial test and 183(9.8\%) had a negative response.

Our Results imply that history of NICU admission and Low birth weight $(<1500 \mathrm{gr})$ were significantly associated with hearing impairment as measured by OAE ( $\mathrm{P}<0.001$ for both of them). History of blood exchange due to Hyperbilirubinemia and positive family history of

Table 1. Prevalence potential risk factors among the 1850 newborns that were screened for hearing loss

\begin{tabular}{lcc}
\hline Risk factor & Frequency & Percentage (\%) \\
\hline $\begin{array}{l}\text { Hyperbilirubinemia } \\
\text { requiring blood exchange }\end{array}$ & 8 & 0.4 \\
$\begin{array}{l}\text { Family history of hearing } \\
\text { loss }\end{array}$ & 68 & 3.6 \\
$\begin{array}{l}\text { Birth weight lower than } \\
\begin{array}{l}1500 \text { gm } \\
\text { history of admission for } \\
\text { more than 48 hours in }\end{array}\end{array}$ & 43 & 2.3 \\
NICU & 160 & 8.6 \\
\hline
\end{tabular}


hearing loss were not significantly different between two groups. Table 2 shows various risk factors regarding initial OAE testing and statistical test results comparing two groups.

Table 2. Potential risk factors regarding initial OAE test results

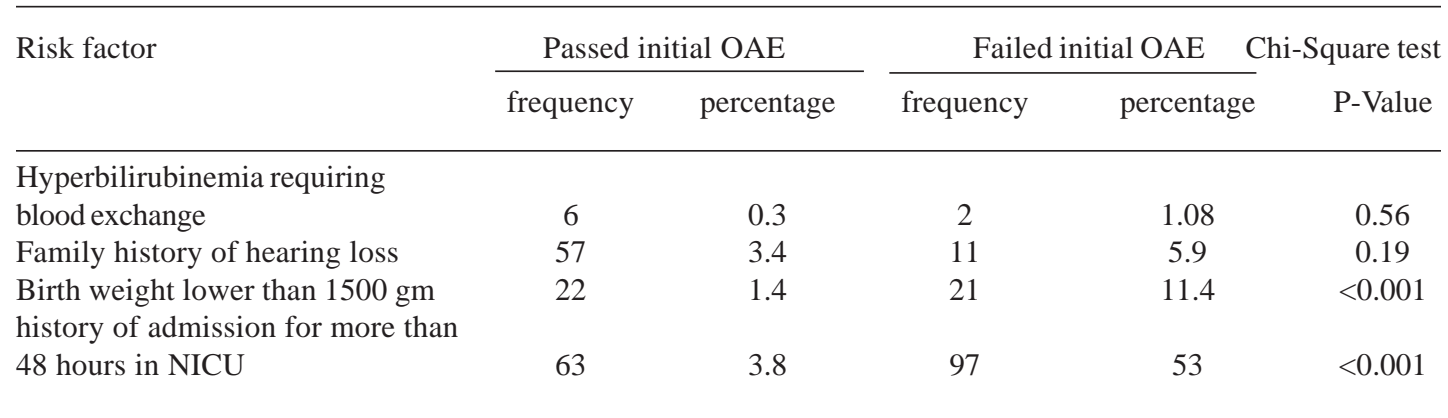

\section{DISCUSSION}

The frequency of initial OAE refers rate for this study was obtained at 9.8\%. Our Results imply that history of NICU admission and Low birth weight $(<1500$ gr) were significantly associated with hearing impairment as measured by OAE. History of blood exchange due to Hyperbilirubinemia and positive family history were not significantly different between two groups. Our OAE refers rate in comparison to the study conducted in Thailand [exclude NICU admission] (6.1\%)[6], India $(6.4 \%)^{7}$ and Spain $(6.7 \%)^{8}$ on one side and Brazil(25.3\%) $)^{9}$, the U.S $(2.3 \%)^{10}$ and Babol,Iran $(10.8 \%)^{21}$ on the other side; refer rate variation may be explained by the number of births per year in each center of the screening ${ }^{10}$ and age in which the first OAE was carried out which may be affected by debris or buid in the external or middle ear in early infancy ${ }^{7,11}$. However, this rate should not exceed upper limit defined by JCIH who recommended that failures in the first stage screening should not surpass $10 \%{ }^{12}$.

In the present study, we pilot a three-step hearing screening with the OAE and ABR. Although OAE screening is quicker, easier and more cost-effective to perform than the ABR, it may be affected by debris or ûuid in the external or middle ear resulting in referral rates of 5 to $20 \%$ when screening is performed between the ûrst 24 hours of life ${ }^{7,11} \mathrm{ABR}$ screening requires the infant to be in a quiet state, but it is not affected by middle or external ear debris. Referral rates lower than $4 \%$ may be achieved when OAE is combined with automated ABR in a two-step screening system ${ }^{11}$ Since OAE is quick and cost effective compared to
$A B R$, retesting with OAE makes the universal screening program more feasible especially when there are large numbers of newborns and low financial support, as in developing countries ${ }^{7}$.

In the present study, the main risk factors for hearing loss were history of NICU admission, followed by low birth weight (Table 2). Risk factors for permanent congenital hearing loss are well established, among them a history of admission to NICU for more than 48 hours, a family history of early childhood permanent deafness, Hyperbilirubinemia and Low birth weight (less than 1500 gr) ${ }^{12-17}$ are more vital.

History of NICU admission as the most important predictor of screening failure in our study, was in agreement with what is found by Uus et al., ${ }^{1}$, whereby screening 169487 infants in England, history of NICU admission were present in $75 \%$ of high-risk infants' identiûed with permanent bilateral hearing loss. Low birth weight was the other significant predictor of OAE failure in our study that was in line with Onoda ${ }^{3}$, Berg ${ }^{16}$ and Pereira ${ }^{18}$. This could be described by risk indicators in low birth weight infants, possibly suffered from asphyxia and in need of long term mechanical ventilation support, ototoxic antibiotic use in these infants may be inevitable to protect from infection and meningitis ${ }^{19}$.

There was not statistically significant association between positive family history of hearing loss and hearing loss; which was in contradiction of Pereira ${ }^{18}$, where screening 502 term newborn, showed low/small weight for gestational age (SGA) is one of the most frequent risk factors for auditory alterations.

There was also no statistically significant 
association with a history of blood exchange due to hyperbilirubinemia and hearing loss; which was against findings of Baradaranfar et al. ${ }^{20}$ where he reports $25 \%$ hearing impairment in neonatal hyperbilirubinemia.

The main limitation of the present study was limiting probable predictors to four major one and not including wide variety of them. The second limitation was the lack of follow up until final diagnosis be made. Though, we couldn't define factors correlated with true hearing loss. Therefore the future step would be a longitudinal evaluation of newborns regarding their hearing loss risk factors in full details, in which each newborn follows until childhood when definitive diagnosis, type of hearing impairment(sensurineural VS. conductive) and effective treatment would be truly described.

\section{CONCLUSION}

History of NICU admission and low birth weight are two significant predictors for OAE failure in south of Iran. So if universal newborn hearing screening is unavailable, targeted screening in high risk infants including those admitted to the NICU and newborns with low birth weight is highly recommended.

\section{REFERENCES}

1. Uus, K. and J. Bamford, Effectiveness of Population-Based Newborn Hearing Screening in England: Ages of Interventions and Profile of Cases. Pediatrics, 2006; 117(5): e887-e893.

2. Yoshinaga-Itano, C., et al., Language of Earlyand Later-identified Children With Hearing Loss. Pediatrics, 19981; 102(5): 1161-1171.

3. Onoda, R.M., M.F.d. Azevedo, and A.M.N.d. Santos, Triagem auditiva neonatal: ocorrência de falhas, perdas auditivas e indicadores de riscos. Brazilian Journal of Otorhinolaryngology, 2011; 77: 775-783.

4. Joint Committee on Infant Hearing 1994 Position Statement. Int J Pediatr Otorhinolaryngol, 1995. 32(3): 265-74.

5. Year 2000 position statement: principles and guidelines for early hearing detection and intervention programs. Joint Committee on Infant Hearing, American Academy of Audiology, American Academy of Pediatrics, American Speech-Language-Hearing Association, and Directors of Speech and Hearing Programs in
State Health and Welfare Agencies. Pediatrics, 2000; 106(4): 798-817.

6. Tungvachirakul, V., et al., Newborn hearing screening at Rajavithi Hospital, Thailand: hearing loss in infants not admitting in intensive care unit. J Med Assoc Thai, 2011; 94(2): S108-12.

7. John, M., A. Balraj, and M. Kurien, Neonatal screening for hearing loss: pilot study from a tertiary care centre. Indian J Otolaryngol Head Neck Surg, 2009; 61(1): 23-6.

8. Gonzalez de Aledo Linos, A., et al., [Universal newborn hearing screening in Cantabria (Spain): results of the first two years]. An Pediatr (Barc), 2005; 62(2): 135-40.

9. Sarafraz, M. and K. Ahmadi, A practical screening model for hearing loss in Iranian school-aged children. World Journal of Pediatrics, 2009; 5(1): p. 46-50.

10. Mehl, A.L. and V. Thomson, The Colorado Newborn Hearing Screening Project, 1992-1999: On the Threshold of Effective Population-Based Universal Newborn Hearing Screening. Pediatrics, 2002; 109(1): p. e7.

11. Isaacson, G., Candidate's Thesis: Universal Newborn Hearing Screening in an Inner-City, Managed Care Environment. The Laryngoscope, 2000; 110(6): 881-894.

12. Hearing, J.C.o.I., Year Position Statement: Principles and Guidelines for Early Hearing Detection and Intervention Programs. Pediatrics, 2007; 120(4): 898-921.

13. Fortnum, H. and A. Davis, Epidemiology of permanent childhood hearing impairment in Trent Region, 1985-1993. Br J Audiol, 1997; 31(6): 409-46.

14. Davis, A. and S. Wood, The epidemiology of childhood hearing impairment: factor relevant to planning of services. Br J Audiol, 1992; 26(2): p. 77-90.

15. Silva, D.P.C.d. and R.H.G. Martins, Analysis of transient otoacoustic emissions and brainstem evoked auditory potentials in neonates with hyperbilirubinemia. Brazilian Journal of Otorhinolaryngology, 2009; 75: p. 381-386.

16. Berg, A.L., et al., Newborn Hearing Screening in the NICU: Profile of Failed Auditory Brainstem Response/Passed Otoacoustic Emission. Pediatrics, 2005; 116(4): p. 933-938.

17. Force, U.P.S.T., Universal Screening for Hearing Loss in Newborns: US Preventive Services Task Force Recommendation Statement. Pediatrics, 2008; 122(1): 143-148.

18. Pereira, P.K., et al., [Newborn hearing screening program: association between hearing loss and risk factors]. Pro Fono, 2007; 19(3): p. 267-78. 
19. Uchoa, N.T., et al., [Prevalence of hearing loss in very low birth weight neonates]. $J$ Pediatr (Rio J), 2003; 79(2): 123-8.

20. Baradaranfar, M.H., et al., Hearing Status in Neonatal Hyperbilirubinemia by Auditory Brain Stem Evoked Response and Transient Evoked Otoacoustic Emission. Acta Medica Iranica,
2011; 49(2): p. 109-112.

21. Haghshenas, M., Zadeh, P. Y., Javadian, Y., Fard, H. A., Delavari, K., Panjaki, H., \& Gorji, H. Auditory screening in infants for early detection of permanent hearing loss in northern Iran. Annals of Medical and Health Sciences Research, 2014; 4(3), 340. 